\title{
Thermoelectric Currents of Earth's Core Generate the Earth's Magnetic Field
}

\author{
Arkadiy Nikolaevich Dmitriev \\ Tyumen Industrial University, Tyumen, Russia \\ Email:dmitriev38@inbox.ru
}

How to cite this paper: Dmitriev, A.N. (2017) Thermoelectric Currents of Earth's Core Generate the Earth's Magnetic Field. International Journal of Geosciences, 8, 1048-1071.

https://doi.org/10.4236/ijg.2017.88059

Received: July 31, 2017

Accepted: August 28, 2017

Published: August 31, 2017

Copyright (c) 2017 by author and Scientific Research Publishing Inc. This work is licensed under the Creative Commons Attribution International License (CC BY 4.0).

http://creativecommons.org/licenses/by/4.0/

\section{cc) (i) Open Access}

\begin{abstract}
The geotemperature gradient is considered as taking main part in generating the Earth's magnetic field. It is shown that geotemperature gradient functions as a generator of both nuclear and mantle thermoelectrical currents thanks to the great temperature difference between the core and the mantle. The movement of those currents is close to the radial direction towards the Earth's crust. However, the nuclear thermocurrents movement tends to cyclically change into opposite one. If the mantle and core thermocurrents move oppositely, the Earth's crust cools down globally and ice age comes, but if they move unidirectionally then global warming comes. The calculation show that the Earth's surface can warm up to not more than $10^{\circ} \mathrm{C}$. The latter, considering how human factor affects the warming of Earth, is incomparably great. There are calculations that show power of the Earth's thermocurrents being enough to generate and maintain the Earth's magnetic field, its modern dynamics and the poles inversion.
\end{abstract}

\section{Keywords}

Geotemperature Gradient, Thermoelectrical Currents, Cyclic

Thermocurrents, Inversion of the Magnetic Poles, Geothermoelectric

Model of the Magnetic Field

\section{Introduction}

At the present time, the most elaborate theory of substantiating electrical currents generation in the planet's metal core is based on hydromagnetic dynamo which works on the self-excitation principle. There are a lot of theoretical and experimental works to prove this model [1]-[6]. However, such model, able not only generate but also fully maintain the Earth's magnetic field for a long while, needs some conditions to be met, such as low viscosity of the core metal fluid, 
convective vertical movements in it, raw magnetic field and so on.

Besides, based on the browsed professional reviews and works [2]-[9] it is obvious that there is still no fundamental and effective principle of generating the Earth's dipole magnetic field for the hydromagnetic dynamo model.

Nevertheless, even in the first half of the last century there were attempts to explain the Earth's magnetic field with thermoelectromotive forces existing in the core, which are conditioned by turbulent convective movements of the core's liquid [10] [11] [12]. However, T. Rikitaki [1] considered those attempts as unlikely thermoelectrical effects, explaining this by absence of distinctness of the core's thermoelectrical power. T. Rikitaki's opinion turned out to be conclusive, since then all the researches of thermoelectrical effects were not taken into consideration in the dynamo theory.

There is another reminder of thermoelectrical currents' role in forming magnetic fields of hot CP stars and, probably, planets in a work of A. Z. Dolginov, where the scientist got the equation of field generation [7]:

$$
\frac{\partial B}{\partial t}=[\nabla,[v \boldsymbol{B}]]+\frac{c^{2}}{4 \pi}\left[\nabla,\left(\frac{1}{\sigma}[\nabla, \boldsymbol{B}]\right)\right]-\left[\nabla, \frac{[\mathbf{j B}]}{e N_{e}}\right]-c[\nabla \eta, \nabla T]
$$

(where $\eta$ is thermoelectrical coefficient).

He thought that the forth from right member $[\nabla \eta, \nabla T]$ was different from zero and generated the star's magnetic field, whereas the first three members could be neglected because they were small and could not be performed at the considered model of moving unmagnetized plasm. His calculations showed that the dipole field of a star on its surface can be about $10^{-4} \mathrm{~T}$. Unfortunately, A. Z. Dolginov never presented a detailed theory of making magnetic fields of space objects with thermoelectrical currents, which are immanent to "hot" objects.

Below, there is the third attempt to reanimate geothermoelectrical currents below. It is shown on the example of Earth that those geothermocurrents, moving directionally inside the conducting shells (the core and the lower mantle) and affected by the great difference of geotemperatures, can generate not raw but real powerful magnetic fields of Earth and other "hot" planets of the solar system, because the phenomenon is universal.

That attempt is based on the results of geophysical field work for many years, experimental and academic research, which let the author elaborate a new model of thermo-electrochemical nature of the Earth's core natural electric field [13] [14]. It is shown that the potential-forming factor of a natural electric field is not the reduction-oxidation zone, but a constantly functioning extraneous source of non-electric origin, which is geotemperature gradient $\partial T / \partial z$. Affected by only the latter $(\partial T / \partial z$ vector is always directed deep into the earth) the anomalies of the natural electric potential, registered at all the Earth's continents, are steadily negative. Besides, only the geotemperature gradient forms two poles along the fall of natural electrical conductors: a negatively charged inner part of conductors and a positively charged outer one (positive pole) in the upper part of the poles, as well as positively charged inner part of conductors and the negatively 
charged outer one (negative pole) in the lower part of the poles. Thermoelectrical currents move inside conductors if the temperature difference applied to the ends of ore bodies is in dynamic state. If the state is static there is no thermoelecrical current, but there is still difference of potentials between the cold and the warmed ends of the conductor.

Hereinafter all the calculations of a planet's magnetic field are based on the known physical laws and known scientific data of inner structure and physical properties of Earth. The results show that the actual Earth's thermoelectrical currents generate and maintain the current geomagnetic field by themselves. Besides, it is the first time when a model specifies complexity of the geomagnetic field, which consists of two parts: main magnetic field of the metal core and additional field of the lower mantle.

Accordingly, the schematic geothermoelectrical model (protomodel) of the Earth's magnetic field is considered for the first time in the author's article [15].

\section{Calculations of Magnetic Field for the Lower Mantle}

To form the geomagnetic model one should procced from the known scientific data of the planet's shells thicknesses, temperature values in the shells and their borders. For example, most of the researchers hold on to the following defining temperatures in the body of our planet: on the depth of about $100 \mathrm{~km}$ the temperature is close $+1800 \mathrm{~K}$, on the depth of about $400 \mathrm{~km}$ (C layer, phase transition zone) the temperature is $+1900 \mathrm{~K}$, on the "mantle-core" border the temperature is $+4000, \ldots,+5000 \mathrm{~K}$, in the core center the temperature is $(+5000, \ldots$, $+6230) \pm 500 \mathrm{~K}[16]$-[21]. As for the planet's electroconductivity, the researchers believe it is distributed in depth (shells) as follows: the upper mantle has low electroconductivity and, predominantly, ionic conduction; in the C layer, semiconducting electroconductivity increases after transiting from the ionic conductivity; the lower's mantle material is an electronic semiconductor; the Earth's core is an electronic conductor with the specific conductance in the range of $(0.1 \div$ $1.0) \times 10^{6} \mathrm{~S} \cdot \mathrm{m}^{-1}$ [16] [17] [21] [22].

That data implies that the globe can be presented as a spherical geothermoelecrical element (further, SGTE) (Figure 1(a)), which ends are the central part of the core and the $\mathrm{C}$ shell (most likely, its middle). The temperature difference of about $+3200 \mathrm{~K}, \ldots,+4500 \mathrm{~K}$ is attached to those ends. Then, according to the Seebeck effect, the thermo-EMF $\Delta \varphi_{T}$ can be calculated [23] [24]:

$$
\Delta \varphi_{T}=\int_{T_{1}}^{T_{2}} \beta \mathrm{d} T
$$

where $\beta$ is the averaged temperature coefficient, which is $0.0001 \mathrm{~V} \cdot \mathrm{deg}^{-1}$. for pure metals, while it is $0.0015 \mathrm{~V} \cdot \mathrm{deg}^{-1}$. for some semiconductors [24].

To find the parameters of the lower mantle thermocurrents $\boldsymbol{I}_{\text {top }}$ the following must be known:

- thermofield intensity $\boldsymbol{E}_{T}$;

- electron concentration per unit volume of the lower mantle ores (it equals $n=$ 


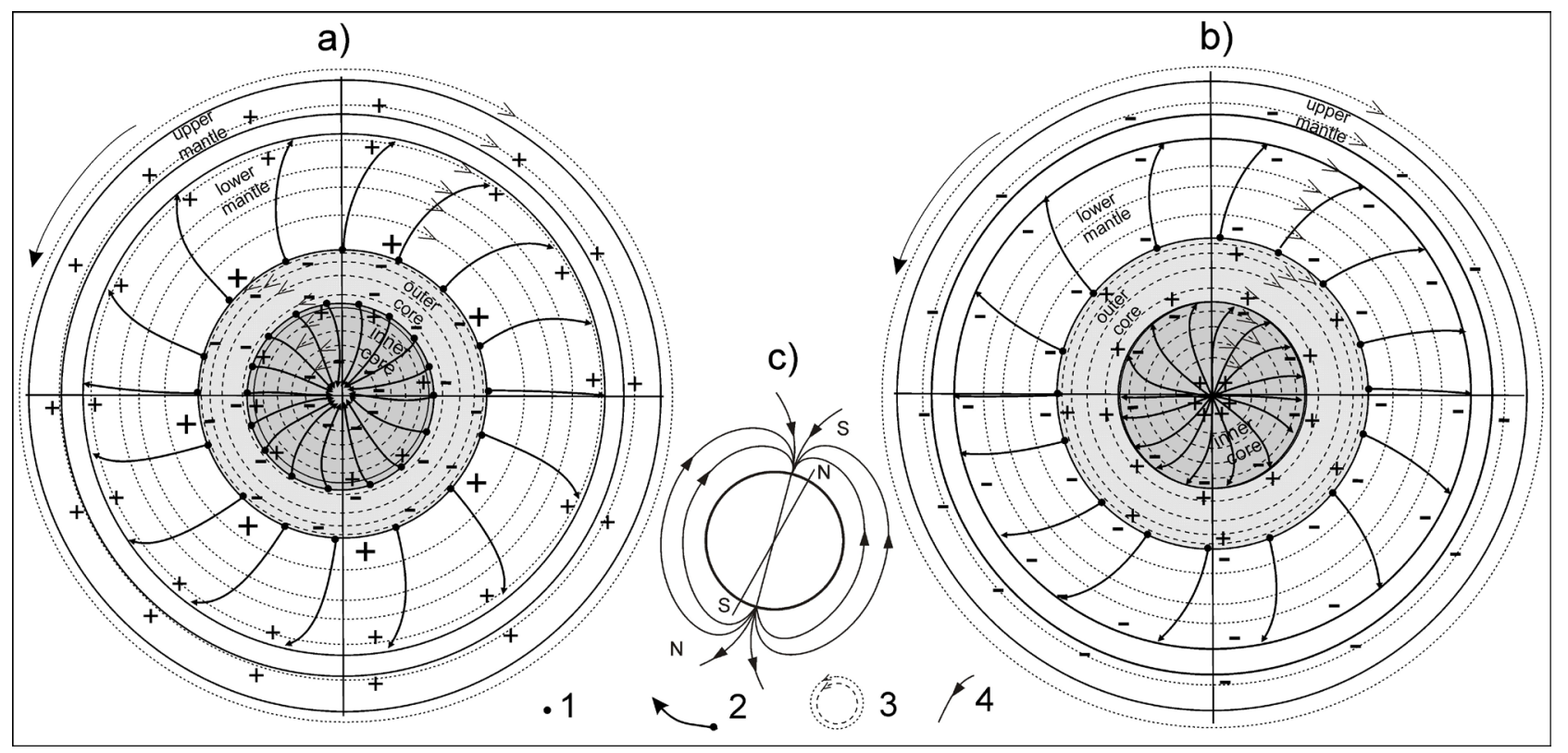

Figure 1. Scheme of the electron flows movement within the spherical metal core and the spherical circle of the lower mantle: (a) projection of traces of oppositely moving electrons of the metal core (to the core's center) and the lower mantle (to the Earth's surface) on the equatorial plane; (b) projection of traces of unidirectionally moving electrons of the metal core and the lower mantle to the Earth's surface on the equatorial plane; (c) dipolar poloidal magnetic field of the Earth. 1: electron; 2: electron trajectories; 3: the lines of force of toroidal field; 4 : the lines of force of self-generated poloidal field.

$$
\begin{aligned}
& 10^{20} \mathrm{~m}^{-3} \text { by default); } \\
& \text { - electron gas drift velocity } v_{d} ; \\
& \text { - electron mean free path in a semiconductor } 1 ; \\
& \text { - current density } j .
\end{aligned}
$$

According to the (2), the maximum thermo-EMF $\Delta \varphi_{T}$ for SGTE is $0.45 \mathrm{~V}$, and the electric field intensity can be found from the following equality:

$$
\boldsymbol{E}_{T}=\Delta \varphi_{T} / l_{\mathrm{SGTE}}, \mathrm{V} / \mathrm{m} ;
$$

where $l_{\mathrm{SGTE}}$ is SGTE radius length, which equals the distance between the planet center and the middle part of the $\mathrm{C}$ shell and is defined as $5438 \mathrm{~km}$ or 5650 $\mathrm{km}$ to the upper mantle.

Hence, the electric field $\boldsymbol{E}_{T}$ generated by the existing temperature difference $\Delta T$ makes planetary flows of "hot" electrons move directionally from the planet center to its outer shells along the radii. At the same time the electron quantity (concentration) in a volume unit of metal $(\mathrm{Fe})$ can be calculated with the formula [24]:

$$
n=\rho N_{A} / A, \mathrm{~m}^{-3},
$$

where $\rho$ is the metal Fe density in the inner core, $\left(12.2 \mathrm{~g} \cdot \mathrm{cm}^{-3}\right) ; N_{A}$ is the Avogadro constant, $6.02 \times 10^{23} \mathrm{~mol}^{-1}$; $A$ is atomic mass Fe (55.847 g). Substituting that data into the (4) we get $n=1.32 \times 10^{29} \mathrm{~m}^{-3} . n$ should be compared to the calculation for the real conditions when electron gas is in free state at pressures $p$, that corresponds to the metal core, i.e. at $p=3.55$ million atm [25] [26] [27]: 


$$
n=\left(5 \frac{m_{e}}{\hbar^{2}}\left(3 \pi^{2}\right)^{-2 / 3}\right)^{3 / 5} p^{3 / 5}
$$

Knowing that electron mass $m_{e}=9.11 \times 10^{-31} \mathrm{~kg}$ and $p=3.59 \times 10^{11} \mathrm{~Pa}$ a new magnitude can be found $n=3.25 \times 10^{29} \mathrm{~m}^{-3}$. Despite there is a slight discrepancy between magnitudes $n_{i}$ (just 2.5 times), the magnitude $n=3.25 \times 10^{29} \mathrm{~m}^{-3}$ is used for the further calculations, as it meets the real planet conditions most. In its turn, the total sum of electron gas in the metal core is defined as $m_{\Sigma}=\frac{4}{3} \pi R_{c}^{3} m_{e} n=5.09 \times 10^{19} \mathrm{~kg}$.

The same must be performed for the lower mantle, spherical shell circle thickness is $\Delta R_{l m}=2.22 \times 10^{6} \mathrm{~m}, n=1 \times 10^{20} \mathrm{~m}^{-3}$ (average value for semiconductors from $5 \times 10^{19} \mathrm{~m}^{-3}$ to $5 \times 10^{20} \mathrm{~m}^{-3}[28]$ ), the electron mass $m_{e}$ is the same. Then $m_{\Sigma l m}=4.35 \times 10^{9} \mathrm{~kg}$.

To calculate the electron gas drift velocity $\boldsymbol{v}_{d}$, according to the quantum theory of the electrical conductivity of metals, the following formula should be used [24] [26] [27] [29] [30]:

$$
\boldsymbol{v}_{d}=\frac{e \boldsymbol{E}_{T} l}{2 m v}, \mathrm{~m} \cdot \mathrm{s}^{-1},
$$

where $e$ is the effective electron charge, $C\left(1.6 \times 10^{-19}\right) ; m$ is the effective electron mass, $\mathrm{kg}\left(0.91 \times 10^{-30}\right) ; \mathrm{l}$ is the electron mean free path, it equals

$$
l=\frac{\sigma \hbar\left(3 \pi^{2}\right)^{1 / 3}}{e^{2} n^{2 / 3}}, \mathrm{~m} ;
$$

where $\sigma$ is the planet's core electroconductivity, $\mathrm{S} / \mathrm{m}$;

$\hbar$ is the Plank's constant, $1.05 \times 10^{-34}, \mathrm{~J} \cdot \mathrm{s}$;

$\boldsymbol{v}$ is the average velocity of electrons thermal movement, it can be derived from the formula:

$$
v=\sqrt{\frac{8 k T}{\pi m}}, \mathrm{~m} \cdot \mathrm{s}^{-1}
$$

where $k$ is the Boltzmann constant, $1.38 \times 10^{-23} \mathrm{~J} / \mathrm{K}$;

As seen, it is necessary to calculate the velocity of the electron thermal movement at $\mathrm{T}=6000 \mathrm{~K}$ preliminary, according to (8), to calculate $\boldsymbol{E}_{T}$ and the electron mean free path $l$ between their concussions with the crystal cell to find $v_{d} \cdot l$ directly depends on the metal core's electroconductivity $\sigma$, which can be taken as $10^{5} \mathrm{~S} / \mathrm{m}$ as the smallest magnitude from the above interval $(0.1 \div 1.0) \times$ $10^{6} \mathrm{~S} \cdot \mathrm{m}^{-1}$. Substituting the corresponding values into (8), (7) and (6) one will get $\boldsymbol{v}=4.81 \times 10^{5} \mathrm{~m} \cdot \mathrm{s}^{-1}, \quad l=2.7 \times 10^{-11} \mathrm{~m}$ and drift velocity of the electron gas flow $v_{d}=4.79 \times 10^{-13} \mathrm{~m} \cdot \mathrm{s}^{-1}$ respectively. The value $\boldsymbol{E}_{T}$ of the latter was $9.73 \times 10^{-8}$ $\mathrm{V} / \mathrm{m}:\left\{\left(0.0001\left(\mathrm{~B} \times \mathrm{K}^{-1}\right) \times 5500(\mathrm{~K}) /\left(5650 \times 10^{3}\right)(\mathrm{M})\right\}\right.$ for the interval "metal core center-lower mantle- $1 / 2$ of the $\mathrm{C}$ shell". To calculate $\boldsymbol{E}_{T}$ two parameters were used: 1) radius of the shells $\mathrm{G}+\mathrm{F}+\mathrm{E}+\mathrm{D}+1 / 2 \mathrm{C}$, which is about $5650 \mathrm{~km}$, and 2) the temperature difference $\Delta T$ between the planet center and the middle border of the C shell, which is close to $5500 \mathrm{~K}$. 
The density of the lower mantle thermoelectrical currents $j$ can be found from the formula, according to [24] [26] [27] [29] [30] [31]:

$$
\boldsymbol{j}=e^{2} n \boldsymbol{E}_{T} \frac{l}{p_{F}}
$$

where $p_{F}$ is Fermi momentum, defined as:

$$
p_{F}=\hbar\left(3 \pi^{2} n\right)^{\frac{1}{3}}
$$

Now the lower mantle thermocurrents $I_{\text {top }}$ must be quantified, as well as the amplitude of the magnetic field they generate. The following must be taken into consideration: 1) the ores are semiconductors, 2) the specific conductance of the mantle solid ores (semiconductors) is a way lower than the core's one, and it is $0.1 \div 10.0 \mathrm{~S} \cdot \mathrm{m}^{-1}[22]$, but there is a more specific range $\left(0.1 \div 1.0 \mathrm{~S} \cdot \mathrm{m}^{-1}[32]\right)$ of its electroconductivity values, based on the inversion of the world net geomagnetic data, 3) according to the statistics, electron concentration in semiconductors is just $10^{20} \mathrm{~m}^{-3}[28]$, generally.

Then the total value of the lower mantle thermocurrents $I_{\text {top }}$, coming through its outer spherical surface $S_{D}$ with the radius $R_{D}$ can be derived from the following formula:

$$
\boldsymbol{I}_{\text {top }}=\mathbf{j} S_{D}
$$

And, finally, according to the Biot-Savart-Laplace law, the Earth's magnetic induction $\boldsymbol{B}_{T T}^{\text {top }}$ on the bottom surface equator can be calculated:

$$
\mathrm{d} \boldsymbol{B}_{T T}^{\text {top }}=\frac{\mu_{0} \boldsymbol{I}_{\text {top }} \mathrm{d} R_{D} \sin 90^{\circ}}{4 \pi R_{\text {Earth }}^{2}}
$$

However, the magnetic moment of the current element $I_{\text {top }} \mathrm{d} R_{D}$ is considered here only in a one-dimensional space towards the current movement along the radius $R_{D}$. Integration over $\mathrm{d} R_{D}$ allows to find the total of the current elements $I_{\text {top }} R_{D}$ just along the way $R_{D}$. This won't go for our case, when the radial currents, like $I_{\text {low }}$ move from the source (sphere's center) to the interface with the lower mantle spherical surface, directed azimuthally from 0 to $4 \pi$ in a spherical conductor. There is no decision on valuation magnetic induction when currents move radially in a spherical conductor in technical literature.

That's why it is better to consider the following model. A small spherical conductor with the radius $\mathrm{d} R_{i}$ is put into the spherical conductor with the radius $R_{\Sigma}$. The currents, moving from the spheres center make a magnetic field in the volume of the initial small sphere. That field is always directed to its volumetric surface tangentially. Then, according to the circulation theorem, $\mathrm{d} \boldsymbol{B} \cdot \frac{4}{3} \pi \mathrm{d} R_{i}^{3}=\mu_{0} \mu_{r} \boldsymbol{I}_{i} \cdot 4 \pi \mathrm{d} R_{i}^{2}$ where the currents $\boldsymbol{I}_{i}$, coming through the small sphere surface $4 \pi \mathrm{d} R_{i}^{2}$. When the current is distributed evenly over the sphere's section $\boldsymbol{I}_{i}=\boldsymbol{I}_{\text {low }}\left(\frac{\mathrm{d} R_{i}}{R_{\Sigma}}\right)^{2}$. Hence, after substituting and shortening, here is the Biot-Savart formula for calculating the magnetic field induction inside the 
sphere (metal core) as the following rationalized form:

$$
\mathrm{d} \boldsymbol{B}_{T T}^{\text {low }}=\frac{3 \mu_{0} \mu_{r} \boldsymbol{I}_{\text {low }} \mathrm{d} R_{i}}{4 \pi R_{\Sigma}^{2}} \text { or } \boldsymbol{B}_{T T}^{\text {low }}=\frac{3 \mu_{0} \mu_{r} \boldsymbol{I}_{\text {low }} R_{\Sigma}}{4 \pi R_{\text {Earth }}^{2}} \sin \alpha,
$$

where $R_{\text {Earth }}$ is the Earth's radius, $R_{\Sigma}$ is the metal core radius.

In its turn, the magnetic field on the Earth's surface for the lower mantle spherical layer can be calculated with considering the thickness of that layer $\Delta R_{D}$, which is denoted as $\mathrm{d} R_{D}$ in (12).

$$
\boldsymbol{B}_{T T}^{\text {top }}=\frac{3 \mu_{0} \mu_{r} \boldsymbol{I}_{\text {top }} \Delta R_{D}}{4 \pi R_{l m}^{2}} \sin \alpha
$$

The heat $Q$, which is produced in the lower mantle $V_{l m}$ because thermocurrents interact with active resistance of this mantle's ores. It can be found from the following formula [23]:

$$
Q_{l m}=\frac{1}{\sigma} j^{2} V_{l m} \Delta t
$$

where $j$ is the current density in the lower mantle, A. $\mathrm{m}^{-2} ; \sigma$ is the lower mantle's electroconductivity $\mathrm{Sm}^{-1} ; \Delta t$ is the time of producing heat for $31,536,000 \mathrm{c}$ (year); $V_{l m}$ is the volume of the lower mantle's spherical circle.

All the calculations for the lower mantle, including the used constants, are tabulated to Table 1 .

As seen from the table, the value of the magnetic induction $\boldsymbol{B}_{T T}^{\text {top }}$ on the Earth's surface is $\sim 4.62 \times 10^{-6} \mathrm{~T}$, which is much lower than the really measured for the same terrestrial conditions $B_{0}=3.4 \times 10^{-5} \mathrm{~T}$. The heat $Q$, which is produced in the lower mantle volume and determined by thermocurrents $I_{t o p}$, is $2.84 \times 10^{14} \mathrm{~J}$ per year $\left(2.84 \times 10^{21} \mathrm{erg}\right.$ per year $)$, and this is much lower than the thermal heat loss of the planet per year, which is determined by the value of $3 \times$ $10^{21}$ J per year $\left(3 \times 10^{28}\right.$ erg per year $)$.

\section{Magnetic Field Calculations for the Metallic Core of the Earth}

Analogic calculations were performed for the thermocurrents $I_{l o w}$ moving under the influence of thermoelectrical field $\boldsymbol{E}_{T}$ inside the metal core according to (3) too. To calculate its value two main parameters were taken into consideration: 1 ) the metal core radius, which is $3500 \mathrm{~km}$ (sum of thicknesses of the inner core, of the transitive F zone and the outer core) and 2) the discussed below difference of temperature $\Delta T$ between the center of the planet and the border "core-lower mantle".

According to the literary sources the magnitude $\Delta T$ is for the metal core is quite uncertain and fluctuates within extreme values from $0 \mathrm{~K}$ to $1957 \mathrm{~K} \pm 227 \mathrm{~K}$. At the same time, it is known from the same sources that such factors as pressure, electroconductivity, thermal conductivity in the metal core are particularly high, and the electron concentration doesn't practically depend on tem- 
Table 1. Calculation of electrical and magnetic parameters of Earth's lower mantle.

\begin{tabular}{|c|c|c|c|}
\hline Constants and calculated parameters & Units & $\begin{array}{l}\text { Used formulas, } \\
\text { their numbers }\end{array}$ & $\begin{array}{l}\text { Calculation } \\
\text { results }\end{array}$ \\
\hline$\mu_{0}$ & $\mathrm{H} / \mathrm{m}$ & & $1.26 \times 10^{-6}$ \\
\hline $\begin{array}{l}\text { Distance between the middle point } \\
\text { of the lower mantle layer and the } \\
\text { bottom surface, } R_{\mathrm{HM}}\end{array}$ & $\mathrm{m}$ & & $6.37 \times 10^{6}$ \\
\hline $\begin{array}{l}\text { Radius of the lower mantle } \\
\text { outer surface, } R_{D}\end{array}$ & $\mathrm{~m}$ & & $5.68 \times 10^{6}$ \\
\hline Lower mantle layer thickness, $\Delta R_{D}$ & $\mathrm{~m}$ & & $1.9 \times 10^{6}$ \\
\hline $\begin{array}{c}\text { Spherical surface } S_{D} \text { area } \\
\text { with radius } R_{D}\end{array}$ & $\mathrm{~m}^{2}$ & $S_{D}=4 \pi R_{D}^{2}$ & $4.05 \times 10^{14}$ \\
\hline $\begin{array}{l}\text { Thermofield } \boldsymbol{E}_{T} \text { density in the lower } \\
\text { mantle } \mathrm{D} \text { at } \Delta T=4000^{\circ} \mathrm{C}\end{array}$ & $\mathrm{V} / \mathrm{m}$ & $\begin{array}{c}\quad \boldsymbol{E}_{T}=\beta \cdot \Delta T / \Delta R_{D},(3) \\
\text { where } \beta=0.0003 \mathrm{~V} / \mathrm{deg} .\end{array}$ & $1.58 \times 10^{-7}$ \\
\hline Plank's constant, $\hbar$ & $\mathrm{J} \cdot \mathrm{s}$ & & $1.05 \times 10^{-34}$ \\
\hline $\begin{array}{l}\text { Electron concentration in a unit } \\
\text { volume of the lower mantle ores, } n\end{array}$ & $\mathrm{~m}^{-3}$ & & $1.0 \times 10^{20}$ \\
\hline Electron charge, $e$ & $\mathrm{C}$ & & $1.6 \times 10^{-19}$ \\
\hline Electron mass, $m_{e}$ & $\mathrm{~kg}$ & & $9.1 \times 10^{-31}$ \\
\hline Lower mantle electroconductivity, $\sigma$ & $\mathrm{S} / \mathrm{m}$ & & 0.4 \\
\hline Fermi momentum, $p_{F}$ & $\mathrm{~m} \cdot \mathrm{kg} / \mathrm{s}$ & $p_{F}=\hbar\left(3 \pi^{2} n\right)^{1 / 2}$ & $1,51 \times 10^{-27}$ \\
\hline Electron mean free path, $I$ & $\mathrm{~nm}$ & $l=\frac{\sigma \hbar\left(3 \pi^{2}\right)^{1 / 3}}{e^{2} n^{2 / 3}} 10^{9}$ & 0.237 \\
\hline Current density, $j$ & $\mathrm{~A} / \mathrm{m}^{2}$ & $\boldsymbol{j}=e^{2} n \boldsymbol{E}_{T} \frac{l}{p_{F}}$ & $6.34 \times 10^{-8}$ \\
\hline $\begin{array}{l}\text { Total amount of current of lower } \\
\text { mantle D coming through the } S_{D} \\
\text { surface, } I_{\text {top }}\end{array}$ & A & $\boldsymbol{I}_{\text {top }}=\boldsymbol{j} S_{D}$ & $2.57 \times 10^{7}$ \\
\hline $\begin{array}{l}\text { Magnetic induction on the Earth's } \\
\text { bottom surface } \boldsymbol{B}_{T T}^{\text {top }} \text { (according } \\
\text { to the measurements, } \boldsymbol{B}_{0} \text { is } \\
3.4 \times 10^{-5} \mathrm{~T} \text { on the equator) }\end{array}$ & $\mathrm{T}$ & $\boldsymbol{B}_{T T}^{\text {top }}=\frac{3 \mu_{0} \boldsymbol{I}_{t o p} \Delta R_{D}}{4 \pi R_{r M}^{2}} \sin \alpha$ & $4.62 \times 10^{-6}$ \\
\hline $\begin{array}{l}\text { The heat, emitted in the lower } \\
\text { mantle by the thermocurrents } \\
\qquad I_{\text {top }} \text { in a year, } Q_{l m}\end{array}$ & J·year & $Q_{l m}=\frac{1}{\sigma} J^{2} V_{l m} \Delta t$ & $2.84 \times 10^{14}$ \\
\hline
\end{tabular}

perature [33]. It is also known that the velocity of seismic P-waves lengthwise the inner core radius doesn't practically change and is about $11.2 \mathrm{~km} \cdot \mathrm{s}$, though the pressure changes from 320 to $360 \mathrm{GPa}$ [18]. On the assumption of the said, temperature difference of $2000 \mathrm{~K}$ inside the metal core body is unlikely. Considering this and taking the core cooling close to $50 \mathrm{~K} \times\left(10^{9}\right)^{-1}$ years [34], there are grounds to take the real value $\Delta T$ for the metal core as $10 \mathrm{~K}$ for the first approximation. This amplitude of the temperature difference between coldnesses (ice ages) and warmings on the Earth's surface is also in the works [35] [36]. That temperature difference is specified in the V. M. Kotlyakov's work as "range 
of the isotopic curve oscillations from glacial periods to interglacial ones equals $10^{\circ} \mathrm{C}$ in temperature" [37]. But there is a work where the temperature difference is defined as $14 \mathrm{~K}$ on the time period from " 65 million years ago till today" [38].

Now let us calculate electric, magnetic and thermal parameters of the solid core, which has temperature dynamics. To do this, let us use the mentioned formulas (2)-(11) (13) (15).

In particular, we must use the initial data when calculating:

$$
\mu_{0} \mu_{\mathrm{Fe}}=1.26 \times 10^{-6} \mathrm{H} / \mathrm{m} \text {; }
$$

Earth's radius, $R_{\text {Earth }}=6.37 \times 10^{6}, \mathrm{~m}$;

Inner core radius, $R_{G}=1.4 \times 10^{6}, \mathrm{~m}$;

Total radius, $R_{\Sigma}=R_{G}+\Delta R_{F}+\Delta R_{E}=3.65 \times 10^{6}, \mathrm{~m}$;

Spherical surface $S_{G}$ area with radius $R_{G}:=4 \pi R_{G}^{2}=2.46 \times 10^{13}, \mathrm{~m}$;

Core electroconductivity, $\sigma=5.0 \times 10^{5} \mathrm{~S} / \mathrm{m}$.

From the formulas (3) (4) (5) (7) (9) (10) accordingly we have:

Thermofield density of the Earth's core at the temperature difference $\Delta T=$ $10^{\circ} \mathrm{C}$ and radius $R_{\Sigma} \quad \boldsymbol{E}_{T}=2.86 \times 10^{-10} \mathrm{~V} / \mathrm{m}$;

Electron concentration in a unit volume of metal $(F e), n_{1}=1.32 \times 10^{29} \mathrm{~m}^{-3}$, $n_{2}=3.25 \times 10^{29} \mathrm{~m}^{-3}$;

Fermi momentum, $p_{F}=1.41 \times 10^{-23} \mathrm{~m} \cdot \mathrm{kg} / \mathrm{s}$;

Electron mean free path, $l=0.85 \mathrm{~nm}$.

Substituting the corresponding meanings of the calculated parameters to the current density formula (9), we get $\boldsymbol{j}=1.43 \times 10^{-4} \mathrm{~A} / \mathrm{m}^{2}$. From the formula (11) we can find the total amount of current of the inner core $\mathrm{G}$ :

$\boldsymbol{I}_{\text {low }}=\boldsymbol{j} S_{G}=3.52 \times 10^{9} \mathrm{~A}$.

According to the formula (15) let us additionally calculate the heat $Q_{b c}$ produced by the thermocurrents $I_{\text {low }}$ which is $2.25 \times 10^{14} \mathrm{~J}$ year $\left(2.25 \times 10^{21} \mathrm{erg}\right.$ per year) and is comparable with the thermocurrents $\boldsymbol{I}_{\text {top }}$ heat in magnitude. There is also a calculation of the Earth's magnetic momentum $M=4 \pi R_{G}^{2} \boldsymbol{I}_{\text {low }}$, which is $8.67 \times 10^{22} \mathrm{~A} \cdot \mathrm{m}^{2}$ when the current $I_{\text {low }}$ is $3.52 \times 10^{9} \mathrm{~A}$ and the spherical surface at the solid core radius is $R_{G}=1400 \mathrm{~km}$. That is close to the known magnitude $M=8.2 \times 10^{22} \mathrm{~A} \cdot \mathrm{m}^{2}$.

For the readers' convenience, all the calculations are presented in the compact Table 2.

The table shows that the thermocurrents $I_{\text {low }}$ are all-sufficient, they are able not only generate the main dipole field of Earth $\boldsymbol{B}_{T T}^{\text {low }}$, but to maintain it for a long time at $3.64 \times 10^{-5} \mathrm{~T}$ level. This value is calculated for the points of Earth on its equator and, as seen, it is close to the real and modern intensity of the EMF. At the same time, the heat, produced by the thermocurrents $I_{\text {low }}$ is only $Q_{b c}=2.25 \times 10^{14}$ J per year $\left(2.25 \times 10^{21}\right.$ erg per year $)$ and is comparable to the heat of the thermocurrents $\boldsymbol{I}_{\text {top }}$. The Earth's magnetic moment was also calculated as $M=4 \pi R_{G}^{2} \boldsymbol{I}_{\text {low }}$. At the current $\boldsymbol{I}_{\text {low }}$ of $3.52 \times 10^{9} \mathrm{~A}$ and spherical surface with the solid core's radius of $R_{G}=1400 \mathrm{~km}$ (see in Table 2) it is $8.67 \times 10^{22}$ 
Table 2. Calculation of electrical and magnetic parameters of Earth's metal core.

\begin{tabular}{|c|c|c|c|}
\hline Constants and calculated parameters & Units & $\begin{array}{c}\text { Used formulas, their } \\
\text { numbers }\end{array}$ & $\begin{array}{l}\text { Calculation } \\
\text { results }\end{array}$ \\
\hline $\begin{array}{c}\mu_{0} \mu_{\mathrm{Fe}}, \text { where } \mu_{\mathrm{Fe}}=1 \\
\text { (Tabove the Curie point) }\end{array}$ & $\mathrm{H} / \mathrm{m}$ & & $1.26 \times 10^{-6}$ \\
\hline Earth's radius, $R_{\text {Earth }}$ & $\mathrm{m}$ & & $6.37 \times 10^{6}$ \\
\hline Inner core radius, $R_{G}$ & $\mathrm{~m}$ & & $1.4 \times 10^{6}$ \\
\hline Total radius, $R_{\Sigma}=R_{G}+\Delta R_{F}+\Delta R_{E}$ & $\mathrm{~m}$ & & $3.65 \times 10^{6}$ \\
\hline $\begin{array}{l}\text { Spherical surface } S_{G} \\
\text { area with radius } R_{\mathrm{G}}\end{array}$ & $\mathrm{m}^{2}$ & $S_{G}=4 \pi R_{G}^{2}$ & $2.46 \times 10^{13}$ \\
\hline $\begin{array}{c}\text { Thermofield } \boldsymbol{E}_{T} \text { density of the Earth's } \\
\text { core at the temperature difference } \\
\qquad T=10^{\circ} \mathrm{C} \text { and radius } R_{\Sigma}\end{array}$ & $\mathrm{V} / \mathrm{m}$ & $\begin{array}{c}\quad \boldsymbol{E}_{T}=\beta \Delta T / R_{\Sigma},(3) \\
\text { where } \beta=0.0001 \mathrm{~V} / \mathrm{deg} .\end{array}$ & $2.86 \times 10^{-16}$ \\
\hline Plank's constant, $\hbar$ & $J \cdot s$ & & $1.05 \times 10^{-34}$ \\
\hline $\begin{array}{c}\text { Electron concentration } \\
\text { in a unit volume of metal }(\mathrm{Fe}) \text {, }\end{array}$ & $\mathrm{m}^{-3}$ & $\begin{array}{c}\left.n=\rho N_{A} / A 4\right) \\
n=\left(5 \frac{m_{e}}{\hbar^{2}}\left(3 \pi^{2}\right)^{-2 / 3}\right)^{3 / 5} p^{3 / 5}\end{array}$ & $\begin{array}{l}1.32 \times 10^{29} \\
3.25 \times 10^{29}\end{array}$ \\
\hline Electron charge, $e$ & $\mathrm{C}$ & & $1.6 \times 10^{-19}$ \\
\hline Electron mass, $m_{e}$ & $\mathrm{~kg}$ & & $9.1 \times 10^{-31}$ \\
\hline Core electroconductivity, $\sigma$ & $\mathrm{S} / \mathrm{m}$ & & $5.0 \times 10^{5}$ \\
\hline Fermi momentum, $p_{F}$ & $\mathrm{~m} \cdot \mathrm{kg} / \mathrm{s}$ & $p_{F}=\hbar\left(3 \pi^{2} n\right)^{1 / 2} \quad(10)$ & $1.41 \times 10^{-2}$ \\
\hline Electron mean free path, $I$ & $\mathrm{~nm}$ & $l=\frac{\sigma \hbar\left(3 \pi^{2}\right)^{1 / 3}}{e^{2} n^{2 / 3}} 10^{9}$ & 0.85 \\
\hline Current density, $j$ & $\mathrm{~A} / \mathrm{m}^{2}$ & $\boldsymbol{j}=e^{2} n \boldsymbol{E}_{T} \frac{l}{p_{F}}$ & $1.43 \times 10^{-4}$ \\
\hline $\begin{array}{l}\text { Total amount of current } \\
\text { of the inner core } \mathrm{G}, \\
\text { Bordered by the } S_{\mathrm{G}} \text { surface, } I_{\text {Iow }}\end{array}$ & A & $\boldsymbol{I}_{\text {low }}=\boldsymbol{j} S_{G}$ & $3.52 \times 10^{9}$ \\
\hline $\begin{array}{l}\text { Magnetic induction on the Earth's } \\
\text { bottom surface } \boldsymbol{B}_{T T}^{\text {low }} \text { (according to } \\
\text { the measurements, } \boldsymbol{B}_{0} \text { is } 3.4 \times 10^{-5} \\
\text { Ton the equator) }\end{array}$ & $\mathrm{T}$ & $\boldsymbol{B}_{T T}^{\text {low }}=\frac{3 \mu_{0} \boldsymbol{I}_{\text {low }} R_{\Sigma}}{4 \pi R_{3}^{2}} \sin \alpha$ & $3.64 \times 10^{-5}$ \\
\hline $\begin{array}{l}\text { The heat, emitted by the } \\
\text { thermocurrents } I_{\text {Iow }} \text { at movement to } \\
\text { the lower mantle per year, } Q_{b c}\end{array}$ & J.year & $Q_{b c}=\frac{1}{\sigma} J^{2} V_{b c} \Delta t$ & $2.25 \times 10^{14}$ \\
\hline
\end{tabular}

$\mathrm{A} \cdot \mathrm{m}^{2}$, which is close to the known value $M=8.2 \times 10^{22} \mathrm{~A} \cdot \mathrm{m}^{2}$.

Let us briefly note, that a toroidal magnetic field forms within the metal core. The field's field lines are spherical circles that do not leave the conducting core (Figure 1(a) and Figure 1(b)). The centrifugal force $F_{C f}$ and the thermo e.m.f. $E_{T}$ have been generating a through channel with electron deficit for 3.5 billion years in the toroidal field in the core center. The channel is the entrance/exit for the poloidal magnetic field which is self-generating in the conductive medium. 
The field is definitely dipole and it has local poles with diameter to $500 \mathrm{~km}$ for entrance/exit of the field lines bundles of the poloidal field with tilt of $90^{\circ}-89^{\circ}$. There is a confirmation for it [39].

\section{Thermoelectrical Model of Earth's Magnetic Field}

First, let us pay attention to a feature of the core: its outer part (outer core) is in a melted state at the temperature $T_{0}$, whereas the inner part (inner core), divided with the transitive $\mathrm{F}$ zone, is in a solid state, but at the lowered temperature $T_{i}$. Hence, we can conclude that the solid core can be colder than the outer one, and its temperature is $T_{i}=T_{0}-10 \mathrm{~K}$. In its turn, it shows that there obviously must be geotemperature gradients, directed oppositely to the melted outer core. Those gradients generate thermoelectric currents "outer core-lower mantle" $\boldsymbol{I}_{\text {top }}$, directed oppositely to the Earth's surface, and “outer core-inner (solid) core's center" $I_{\text {low }}$ to the planet's center (Figure 1(a)). On the assumption of the known connection between an electrical current and the heat, produced by it, the inner core temperature $T_{i}$ is expected to get $T_{0}$, and then get higher than $T_{0}$ i.e. $T_{i}>T_{0}$. Such happens when the flows of the thermocurrents $I_{l o w}$ move to the Earth's center and their electron concentration $n$ in the inner core because of the absence of drains (outer borders) and, consequently, absence of dissipation of the charge energy. As a result, current density increases, which contributes to higher producing of Joule heat and its accumulation in the Earth's central part. Eventually, the inner core's temperature $T_{i}$ reaches the temperature of the melted core $T_{0}\left(T_{i}=T_{0}\right)$ and at this moment the field intensity $\boldsymbol{E}_{T}$ gets equal to zero $\left(\boldsymbol{E}_{T}=0\right)$ in the "outer core-inner core" branch. From that very moment thermocurrents $I_{l o w}$ stop moving, and the Earth's dipole magnetic field disappears, but the lower mantle magnetic field $\boldsymbol{B}_{T T}^{\text {low }}$ remains.

Nevertheless, thermocurrents $I_{\text {low }}$ of low intensity are able to not only appear for a short time and several times but change their directions to the opposite ones, because the thermal process is not homogeneous at different points of the inner core.

The inner core temperature eventually gets higher and reaches a persistent state $T_{i}>T_{0}$ because of the thermal process inertia. At this state thermocurrents of opposite direction instantly appear and signs of the inner SGTE charges finally change (Figure $1(\mathrm{~b})$ ). From the moment of the persistent state $T_{i}=T_{0}$ thermocurrents $I_{\text {top }}$ and $I_{\text {low }}$ move to the Earth's surface unidirectionally and their mutual current $I$ sums up. Ores of the lower mantle gets extra heat because a part of the thermocurrents $I_{\text {low }}$ permeates in. That heat spreads predominantly to the bottom surface's side, and when it is reached, the Earth's crust and atmosphere reach the mode of dynamic heating gradually. From the other hand, electron flows leave the core, and it slowly cools down after electron concentration gets less. But when the moment of the persistent state $T_{i}<T_{0}$ comes, a new and opposite process begins-thermocurrents $I_{\text {low }}$ go to the inner core and warm it. At the same time the mutual current $I$ decreases and Earth comes into its cooling 
mode, and the dipole magnetic field restores. The cycles repeat.

\section{Briefly about the Cyclicity of Cooling and Warming of the Earth's Crust}

The results of the calculations in Table 2 give us the following. First, the reason why cooling and warming alternate each other on the Earth's crust surface and our planet's atmosphere is the existing cyclic change of thermocurrents in the inner core $\boldsymbol{I}_{\text {low }}$ (Figure 2). Secondly, geomagnetic polarity reversal can happen only when phases "warming-cooling-warming" change, probably, every $10^{5} \div 10^{6}$ years [7]. During the period of these reversals dipole magnetic field $\boldsymbol{B}_{T T}^{\text {low }}$ decreases (or increases) up to its momentary disappearance (increment), at the same time the magnetic pole, created by the lower mantle, always stays as $4.6 \times$ $10^{-6} \mathrm{~T}$ at any reversal sign.

In this connection, there can be made a preliminary estimate of the time interval $\Delta t$ between adjacent coinciding phases of $\boldsymbol{I}_{\text {top }}$ and $\boldsymbol{I}_{\text {low }}$ thermocurrents movement, for example, to the Earth's crust. In this case that interval can correspond to the period of two maximum Earth warmings or cooling if the thermocurrents move in an antiphase direction (Figure 2).

That can be represented by the following model of multidirectional movements of thermocurrents $I_{\text {low }}$ towards the persistently unidirectional movement of thermocurrents $I_{\text {top: }}$ :

$1^{\text {st }}$ cycle: core-lower mantle; $2^{\text {nd }}$ cycle: lower mantle-core; $3^{\text {rd }}$ cycle: core-lower mantle.

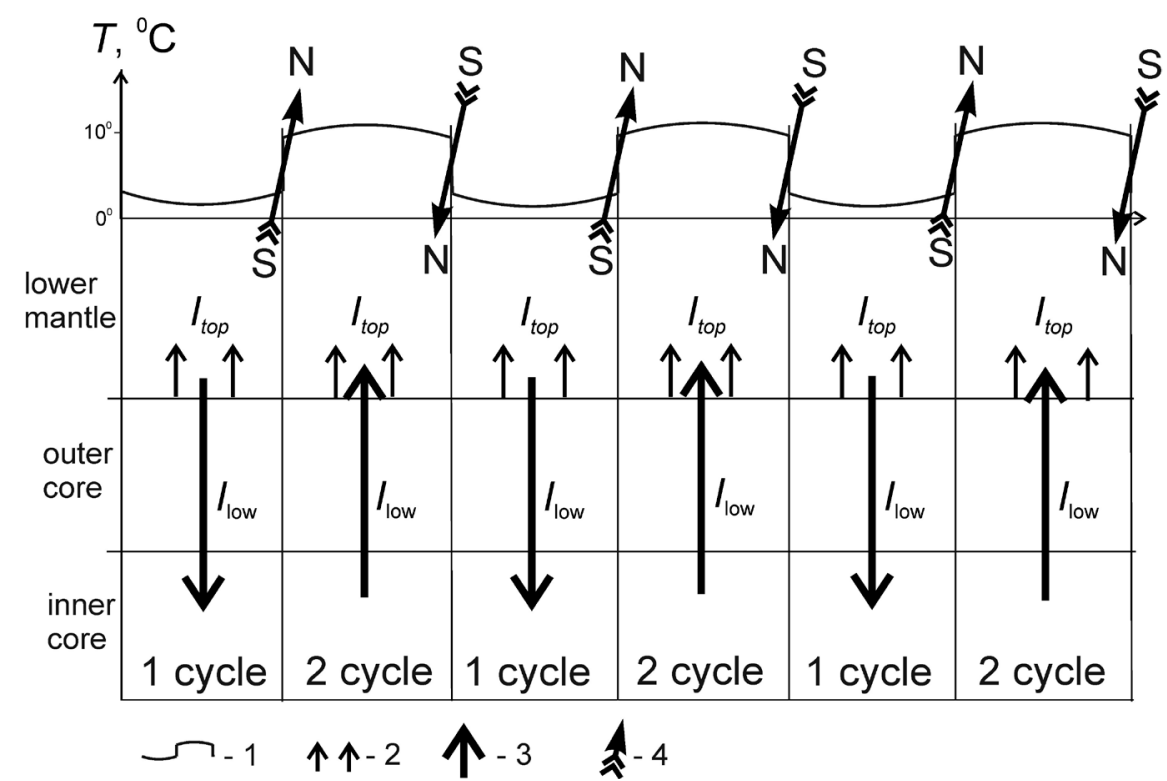

Figure 2. Graph of connection between EMF polarity reversal and warming and cooling periods on Earth with the change of the direction of the planetary currents $I_{\text {low }}$ vectors. 1-graph of the cyclic temperature at the Earth's surface distribution; 2-directed movement of the lower mantle thermocurrents $I_{t o p}$; 3-directed movement of the inner core thermocurrents $I_{\text {low }} ; 4$-magnetic poles position at the EMF reversal. 
For a quantitative estimation of the model one should take into consideration drift velocity $v_{d}$ (7) of electrons, which move directionally in the electric field $\boldsymbol{E}_{T}$ from the inner core's side to the upper mantle (1 ${ }^{\text {st }}, 3^{\text {rd }}$ cycles) and backwards ( $2^{\text {nd }}$ cycle).

However, that velocity is average and it is defined from the interval $\boldsymbol{v}_{d}$ between 0 and max. But if the velocity of an electron after the collision has nothing to do with its velocity before the collision [26], the calculated function of electron distribution according to their real velocities allows to calculate the drift velocity more accurately with the following formula [26] [40] [41]:

$$
\boldsymbol{v}_{d}=\frac{e \boldsymbol{E}_{T} l}{m v}
$$

However the existing scientific argument if it is right to use the formula (6) or the formula (6a) can be resolved only in course of time and only by comparing theoretical calculations with the practice.

All the calculations to define warming periods are in Table 3 with all the needed constants and formulas.

Table 3. Calculation of warming periods on Earth.

\begin{tabular}{|c|c|c|c|}
\hline $\begin{array}{l}\text { Constants and calculated } \\
\text { parameters }\end{array}$ & Units & Used formulas, their numbers & $\begin{array}{l}\text { Calculation } \\
\text { results }\end{array}$ \\
\hline Number of seconds in a year, $C$ & s & & $31,536,000$ \\
\hline The core radius + lower mantle, $R$ & $\mathrm{~m}$ & & $5.65 \times 10^{6}$ \\
\hline $\begin{array}{c}\text { Thermofield } \boldsymbol{E}_{T} \text { density in the } \\
\text { interval core } \mathrm{G} \text {-transition } \\
\text { zone } \mathrm{C} \text { at } \Delta T=5530 \mathrm{~K}\end{array}$ & $\mathrm{~V} / \mathrm{m}$ & $\begin{array}{c}\qquad \boldsymbol{E}_{T}=\beta \cdot \Delta T / R,(3) \\
\text { where } \beta=0.0003 \mathrm{~V} / \mathrm{deg} .\end{array}$ & $2.94 \times 10^{-7}$ \\
\hline Plank's constant, $\hbar$ & $\mathrm{J} \cdot \mathrm{s}$ & & $1.05 \times 10^{-34}$ \\
\hline $\begin{array}{l}\text { Electron concentration in a unit } \\
\text { volume of the lower mantle, } n\end{array}$ & $\mathrm{~m}^{-3}$ & $\begin{array}{l}\text { It is presumed, that the } \\
\text { density of } n \text { in the lower } \\
\text { mantle increases to } 3.25 \times \\
10^{22} \text { when } e \text { moves from the } \\
\text { core to the mantle }\end{array}$ & $3.25 \times 10^{22}$ \\
\hline Electron charge, $e$ & $\mathrm{C}$ & & $1.6 \times 10^{-19}$ \\
\hline Electron mass, $\mathrm{m}$ & $\mathrm{kg}$ & & $9.1 \times 10^{-31}$ \\
\hline Core electroconductivity, $\sigma$ & $\mathrm{S} / \mathrm{m}$ & & $8.3 \times 10^{4}$ \\
\hline Fermi momentum, $p_{F}$ & $\mathrm{~m} \cdot \mathrm{kg} / \mathrm{s}$ & $p_{F}=\hbar\left(3 \pi^{2} n\right)^{1 / 2}$ & $1.04 \times 10^{-26}$ \\
\hline Electron mean free path, 1 & $\mathrm{~nm}$ & $l=\frac{\sigma \hbar\left(3 \pi^{2}\right)^{1 / 3}}{e^{2} n^{2 / 3}} 10^{9}$ & 1039 \\
\hline $\begin{array}{c}\text { Average velocity of electron } \\
\text { thermal motion in a } \\
\text { semiconductor } V, M / C\end{array}$ & $\mathrm{~m} / \mathrm{s}$ & & $\sim 10^{5}$ \\
\hline $\begin{array}{l}\text { Drift velocity of the electron } \\
\text { flow in the field } \boldsymbol{E}_{T}\end{array}$ & $\mathrm{~m} / \mathrm{s}$ & $\boldsymbol{v}_{d}=\frac{e \boldsymbol{E}_{T} l}{m v} \quad(6, \mathrm{a})$ & $5.36 \times 10^{-7}$ \\
\hline $\begin{array}{l}\text { Time from the } 1 \text { st cycle } \\
\text { beginning till its end, } t_{1}\end{array}$ & year & $t_{1}=R_{G} /\left(v_{\partial} \cdot C\right)$ & $8.29 \times 10^{4}$ \\
\hline $\begin{array}{l}\text { Time from the } 1 \text { st cycle beginning } \\
\text { till the end of the } 3^{\text {rd }} \text { cycle, } t_{1-3}\end{array}$ & year & $t_{1-3}=3 t_{1}$ & $2.49 \times 10^{5}$ \\
\hline
\end{tabular}


All the calculations to define warming periods are in Table 3 with all the needed constants and formulas.

It is seen from Table 3 that the period of direct warming is about 83000 years, whereas the time lapse between the consecutive warmings $\Delta t$ is about 249,000 years. The main error of this magnitude is determined by the value of the temperature coefficient $\beta$ and the final electron concentration in the semiconductor when "hot" electrons move out of the core. In our case, the value of $\beta$ for the lower mantle, whose ores are considered to be semiconductors, is taken speculatively, and it is $0.0003 \mathrm{~V} \cdot \mathrm{K}^{-1}$, as in Table 1 , and it is just three times more than the temperature coefficient for pure metals. However, if one takes the possibly minimum magnitude $0.001 \mathrm{~V} \mathrm{deg}^{-1}$. for semiconductors instead of $0.0015 \mathrm{~V}$ $\mathrm{deg}^{-1}$. [29], then the time lapse from the beginning of the warming and its ending will be about 25,000 years, and the time lapse between the warming phases $\Delta t$ will be 75,000 years.

Periods of cooling and warming cycles also change noticeably, if $n$ for the lower mantle ores is increased only by 1 order, i.e. $n=3.25 \times 10^{23} \mathrm{~m}^{-3}$ (the initial value for calculations is taken as $n=3.25 \times 10^{22} \mathrm{~m}^{-3}$ ). Then the period of direct warming is about 385,000 years, and the time lapse between the consecutive warmings $\Delta t$ is now about 1.15 million years.

It appears from the roughly evaluative calculations, that despite the large range of numbers they are still within the assumptive time intervals, which the researchers get by an indirect analysis of geologic and climatological material of our planet, accumulated numerously [37] [42] [43] [44] [45] [46]. According to geological data from different literary sources, the older the planet is, the shorter cooling periods (ice ages) and warming periods get, they fraction into subperiods, which can be explained by cycles getting gradually ordered and steady while the planet's inner structure is forming [44] (Figure 3).

\section{The Calculation of the Expected Temperature Warming of the Earth's Crust}

To solve the task, we should consider the following conditions. Earth is now under a steady nonequilibrium thermodynamic state, because there are pressure and temperature gradients, that can be concluded from the I. R. Prigogine's work [47]. Thermoelectrical currents $\boldsymbol{I}_{\text {Iow }}$ of the solid and the melted cores move to the lower mantle. Their velocity, defined by the electron velocity, is about $2 \times$ $10^{-8} \mathrm{~m} \cdot \mathrm{s}^{-1}$, and their distance, for example, for $10^{3}$ years is not more than $60-70$ $\mathrm{km}$. That thin shell layer, being in the "core-mantle" border zone, is warmed to $4510 \mathrm{~K}$ (the initial temperature on the line of $4500 \mathrm{~K}$ ) by the heat of the core $Q$ thermocurrents (see Table 2). Its difference reaches $10 \mathrm{~K}$, let us denote it as $T_{1}$. Let us take the temperature of the Earth's bottom surface as $T_{2}=273.1 \mathrm{~K}$.

In this connection, a simplified heat-exchanging model of Earth can be represented as a hollow spherical shell with two sides. One of them is the inner one with radius $R_{\Sigma}=3.65 \times 10^{6} \mathrm{~m}$, corresponding the surface of the 


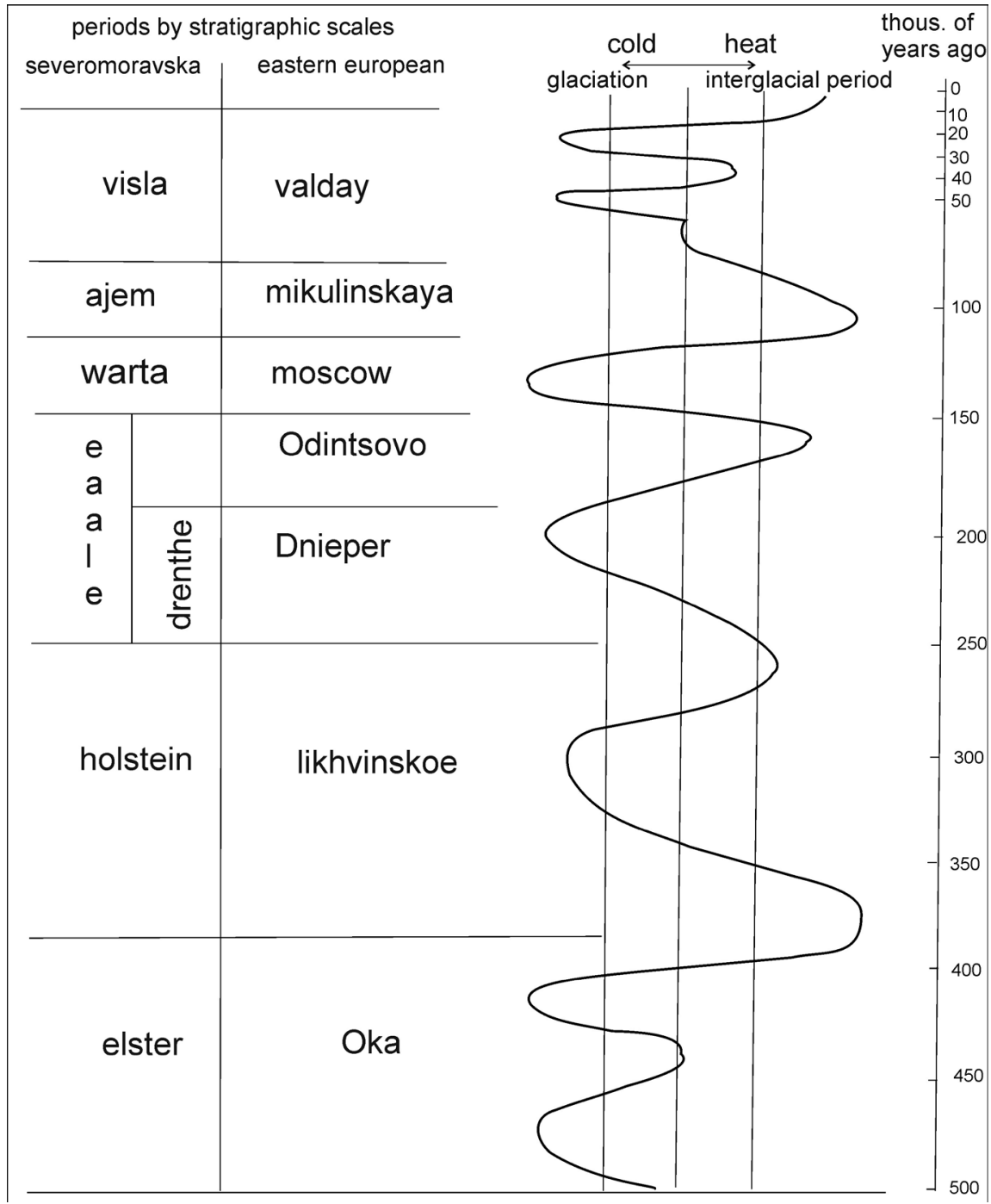

Figure 3. Climatic curve of the East Europe for the last 500 thousand years (the picture was taken from an internet-article "temperature-climatic cyclicity at the anthropogene and its consequences" by V. B. Serebrennikov).

section "core-lower mantle". The other one is the outer side with radius $R_{\text {Earth }}=6.37 \times 10^{6} \mathrm{~m}$, corresponding the bottom surface. The inner side is affected by the inner core heat $Q_{b c}=2.25 \times 10^{14}$ J year (see Table 2). Let us take thermal conductivity coefficient of the spherical shell equal to the constant thermal conductivity coefficient of the lower mantle: $\lambda=2.5 \mathrm{~W}(\mathrm{~m} \cdot \mathrm{K})^{-1}[48]$. At the same time the inner side is overheated with the heat $Q$ by $T_{1}=283.1 \mathrm{~K}$ $\left(10^{\circ} \mathrm{C}\right)$, and the outer side is $T_{2}=273.1 \mathrm{~K}\left(0^{\circ} \mathrm{C}\right)$ at the beginning, but after heating it gets $T_{2}=X \mathrm{~K}$.

To find $T_{2}$ the homogeneous differential heat equation in spherical coordinates can be used [49]:

$$
\nabla^{2} T=\frac{\mathrm{d}^{2} T}{\mathrm{~d} r^{2}}+\frac{2}{r} \frac{\mathrm{d} t}{\mathrm{~d} r}=0
$$

Nevertheless, these values of interglacial periods (warming) or cooling can be 
essentially clarified, if there was exact data of the $\beta$ coefficient value for not only pure metals, but different materials of the planet's shells, more complicated ones.

Here are the border conditions:

$$
\left.\begin{array}{l}
\text { if } r=R_{\Sigma}, T=T_{1} ; \\
\text { if } r=R_{\text {Earth }}, T=T_{2} ;
\end{array}\right\}
$$

Then at the predetermined border conditions the solution of the Equation (16) is the temperature field Equation (17) in the spherical layer of Earth:

$$
T(r)=T_{1}-\frac{T_{1}-T_{2}}{\frac{1}{R_{\Sigma}}-\frac{1}{R_{\text {Earth }}}}\left(\frac{1}{R_{\Sigma}}-\frac{1}{r}\right), R_{\Sigma} \leq r \leq R_{\text {Earth }}
$$

Fourier's law should be used to find the amount of the heat $Q$, coming through the spherical surface $S_{D}$ per unit time [49]:

$$
Q=-\lambda \frac{\mathrm{d} T}{\mathrm{~d} r} S_{D}=-\lambda 4 \pi r^{2} \frac{\mathrm{d} T}{\mathrm{~d} r}
$$

Let us denote the temperature gradient $\mathrm{d} T / \mathrm{d} r$ from (18). If we substitute it to the (19), a new expression can be derived [50] [51]:

$$
Q=\frac{4 \pi \lambda\left(T_{1}-T_{2}\right)}{\frac{1}{R_{\Sigma}}-\frac{1}{R_{\text {Earth }}}}=\frac{2 \pi \lambda\left(T_{1}-T_{2}\right)}{\frac{1}{d_{\Sigma}}-\frac{1}{d_{\text {Earth }}}}=\pi \lambda d_{\Sigma} d_{\text {Earth }}\left(T_{1}-T_{2}\right)
$$

The temperature $T_{2}$ can be found with that expression, if the heat $Q$ is known:

$$
T_{2}=T_{1}-\frac{Q \delta}{\pi \lambda d_{\Sigma} d_{\text {Earth }}}
$$

where $\delta=\frac{\left(d_{\Sigma}+d_{\text {Earth }}\right)}{2}$ is the spherical layer "lower mantle-bottom surface" thickness;

$$
Q=Q_{b c}=2.25 \times 10^{14} / 31536000=7.13 \times 10^{6} \mathrm{~J} .
$$

Substituting the corresponding parameter values into (21) gives us increasing of the temperature on the bottom surface by $T_{2}=273.2 \mathrm{~K}$ when the heat of the core $I_{\text {low }}$ thermocurrents affects the lower mantle permanently. As seen, the minor difference between $T_{2}$ and $T_{1} 9.92 \mathrm{~K}$ can be explained by the fact, that the spherical layer thickness is not great, not much more than 0.37 at the correlation thickness/diameter of the warmed side.

However, to check the calculated $T_{2}$, a more accurate analytical solution of the task of determining the temperature inside the sphere and on its surface at any moment of time should be used [52]. Without speaking much of deducing that solution, here is the final solution of the differential heat equation at the Dirichlet boundary conditions $T(1, F o)=T_{1}=$ const for $X>273.16 \mathrm{~K}$ и $T_{2}=273.16 \mathrm{~K}$ at $\tau=0$ [52] [53]:

$$
T(X, F o)=T_{1}+2\left[T(X, 0)-T_{1}\right] \sum_{n=1}^{\infty}(-1)^{n+1} \frac{\sin \left(\delta_{n} X\right)}{\delta_{n} X} \exp \left[-\left(\delta_{n}\right)^{2} F o\right]
$$


where $F O=\lambda \cdot \frac{\tau}{c_{p}^{\prime} R^{2}}$ is Fourier's number;

$$
\Lambda_{1}=(-1)^{n+1} \frac{\sin \left(\delta_{n} X\right)}{X} \text { is the lambda function; }
$$

$X=r / R$ is the dimensionless radial coordinate of a random point of the sphere;

$r$ is the radial coordinate a random point of the sphere, $\mathrm{m}$;

$R$ is the inherent size of the sphere body, $\mathrm{m}$;

$\tau$ is the time, s;

$c_{p}^{\prime}=\rho \cdot c_{p}$ is the specific volumetric isobaric heat capacity of the lower mantle ores, which is distributed over both the upper mantle and the Earh's crust contingently, $\mathrm{J} \cdot\left(\mathrm{m}^{3} \cdot \mathrm{K}\right)^{-1}$;

$\rho$ is the average density of the ores of the lower mantle, the upper mantle and the Earth's crust, $4500 \mathrm{~kg} / \mathrm{m}^{3}$;

$c_{p}$ is the specific mass isobaric heat capacity, $1260 \mathrm{~J} \cdot(\mathrm{kg} \cdot \mathrm{K})^{-1}[54]$;

$T_{1}$ is the temperature of the inner side (surface) when $X=0.54$ and $\tau=0$ equals $283.2 \mathrm{~K}$;

$\delta_{n}=n \pi$ at $n=1,2, \cdots, \infty$ is nth root of the characteristic equation $\sin \left(\delta_{n}\right)=0$ for the Dirichlet boundary conditions;

$\lambda$ is the thermal conductivity coefficient, it is $2.5 \mathrm{~W} /(\mathrm{m} \cdot \mathrm{K})$ for the lower mantle [54];

Substituting the above numbers into the Equation (22), here is the solution for the temperature, which is demonstrated in Figure 4 and Table 4. As seen from

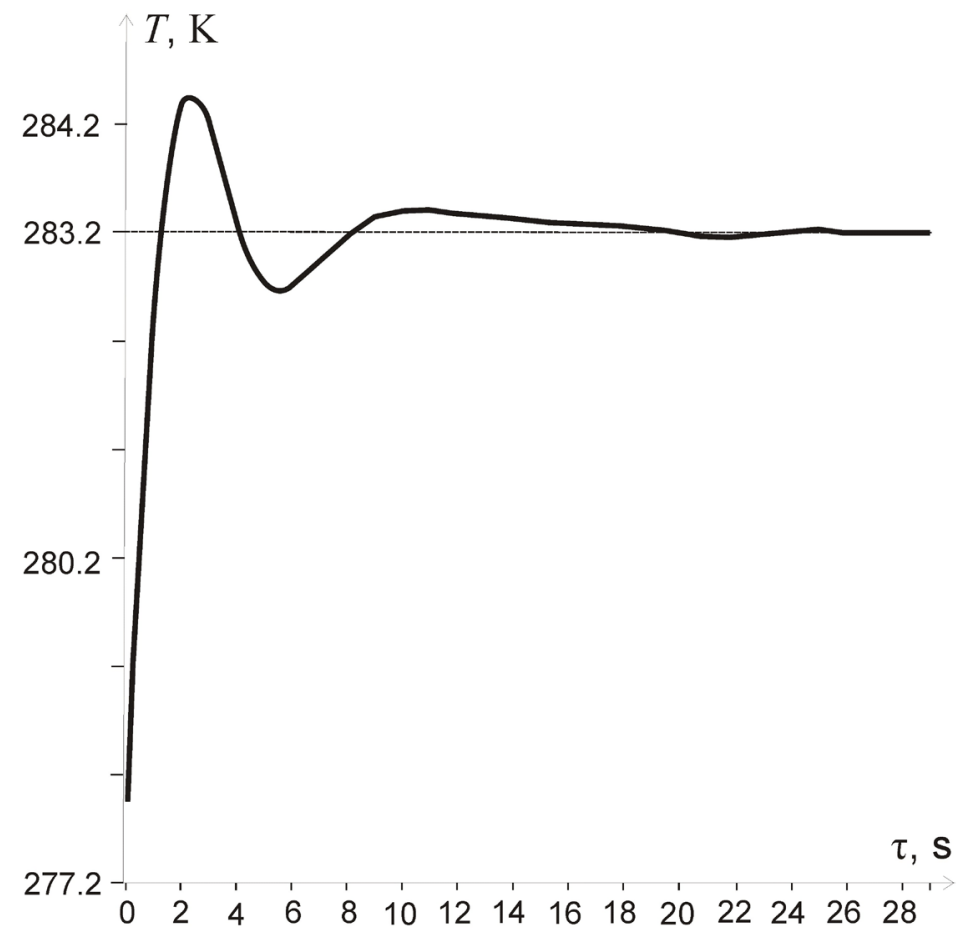

Figure 4. Graph of the temperature of the surface warming by the earth's thermoelectric currents inner core. 
Table 4. Calculation of bottom surface heat temperature by Earth's thermoelectrical currents.

\begin{tabular}{|c|c|c|c|c|c|}
\hline$n$ & $\tau$ & $\delta=n \pi$ & $r$ & $r / R$ & $T(X, F o)=T_{2}$ \\
\hline 1 & 0 & 0 & 3470 & 0.54 & 277.89 \\
\hline 2 & 1 & 1 & 3570 & 0.56 & 282.236 \\
\hline 3 & 2 & 2 & 3670 & 0.58 & 284.338 \\
\hline 4 & 3 & 3 & 3770 & 0.59 & 284.164 \\
\hline 5 & 4 & 4 & 3870 & 0.61 & 283.256 \\
\hline 6 & 5 & 5 & 3970 & 0.62 & 282.691 \\
\hline 7 & 6 & 6 & 4070 & 0.64 & 282.648 \\
\hline 8 & 7 & 7 & 4170 & 0.65 & 282.876 \\
\hline 9 & 8 & 8 & 4270 & 0.67 & 283.125 \\
\hline 10 & 9 & 9 & 4370 & 0.69 & 283.285 \\
\hline 11 & 10 & 10 & 4470 & 0.70 & 283.351 \\
\hline 12 & 11 & 11 & 4570 & 0.72 & 283.357 \\
\hline 13 & 12 & 12 & 4670 & 0.73 & 283.338 \\
\hline 14 & 13 & 13 & 4770 & 0.75 & 283.312 \\
\hline 15 & 14 & 14 & 4870 & 0.76 & 283.29 \\
\hline 16 & 15 & 15 & 4970 & 0.78 & 283.272 \\
\hline 17 & 16 & 16 & 5070 & 0.80 & 283.256 \\
\hline 18 & 17 & 17 & 5170 & 0.81 & 283.238 \\
\hline 19 & 18 & 18 & 5270 & 0.83 & 283.214 \\
\hline 20 & 19 & 19 & 5370 & 0.84 & 283.186 \\
\hline 21 & 20 & 20 & 5470 & 0.86 & 283.155 \\
\hline 22 & 21 & 21 & 5570 & 0.87 & 283.132 \\
\hline 23 & 22 & 22 & 5670 & 0.89 & 283.126 \\
\hline 24 & 23 & 23 & 5770 & 0.91 & 283.14 \\
\hline 25 & 24 & 24 & 5870 & 0.92 & 283.162 \\
\hline 26 & 25 & 25 & 5970 & 0.94 & 283.175 \\
\hline 27 & 26 & 26 & 6070 & 0.95 & 283.169 \\
\hline 28 & 27 & 27 & 6170 & 0.97 & 283.157 \\
\hline 29 & 28 & 28 & 6270 & 0.98 & 283.156 \\
\hline 30 & 29 & 29 & 6370 & 1.00 & 283.159 \\
\hline
\end{tabular}

the latter, the temperature graph goes asymptote at $\tau=20 \mathrm{~s}$ and varies within $(283.125 \div 283.175) \mathrm{K}$ or $(9.966 \div 10.015)^{\circ} \mathrm{C}$, that confirms the pervious calculation enough. Besides, Figure 4 also shows that it takes heat only 20 s. to move from the border "core-lower mantle" to the bottom surface.

Note, that the performed calculations are simplified and preliminary for now, because the taken model does not take into consideration other values of the thermal conductivity coefficients of the transitive zone $\mathrm{C}$ shells, the lower mantle $\mathrm{B}$ and the Earth's crust A. That is why accurate calculations for the spherically 
heterogeneous heat-exchange model of Earth can differ from the obtained results noticeably because the thermocurrens under different continents are heterogeneous.

\section{Features of the Behavior of Earth's Magnetic Field Associated to the Core's Cyclic Thermocurrents}

The calculated magnitude of the magnetic induction $\boldsymbol{B}_{T T}^{\text {low }}$ can be real only if the used physical parameters and constants strictly meet the requirements of the physical law within which one or the other phenomenon can be correctly described, emergence and development of the Earth's magnetic field in particular. The calculations analysis shows that the main element of their conformity is geothermoelectrical field $\boldsymbol{E}_{T}$ with its small intensity according to (3). At the same time, the known scientific conception of a planet's metal core allowed to use the averaged temperature coefficient $\beta$, which is $0.0001 \mathrm{~V} / \mathrm{K}$ for pure metals. The magnitude of the latter affects all the following parameters: $\boldsymbol{E}_{T}, \boldsymbol{j}, \boldsymbol{I}_{\text {low }}$ which form the magnetic induction of the Earth's field $\boldsymbol{B}_{T T}^{\text {low }}$. That is why all the deliberate deviations from this value makes the $\boldsymbol{B}_{T T}^{\text {low }}$ magnitude get too low or extremely high. Hence, the taken magnitude $\beta$ which is close to $0.0001 \mathrm{~V} / \mathrm{K}$ indicates high probability of our planet's core being metal.

Besides, the planet's inner core electroconductivity $\sigma$ affects the $\boldsymbol{B}_{T T}^{\text {low }}$ magnitude, but in a less degree. Thus, for instance, $\sigma$, which was taken by selecting, is equal to $5.0 \times 10^{5} \mathrm{~S} / \mathrm{m}$ and meets the calculated magnitude of the geomagnetic field on the planet's equator, which is $3.64 \times 10^{-5} \mathrm{~T}$. But if one takes the electroconductivity of about 1.0 million $\mathrm{cm} / \mathrm{m}$, the magnetic field on the equator will be $6.98 \times 10^{-5} \mathrm{~T}$, which is much higher than the real magnitude of $B_{0}$. Therefore, the present range of the planet's core electroconductivity $0.1 \div 1.0$ million $\mathrm{S} / \mathrm{m}$ can be constricted to some extent.

Besides, the considered model allows to explain the tilt of the magnet axis toward the Earth's one by the Coriolis forces affecting the electron currents. The preliminary calculation shows that the Coriolis forces can displace the normal from the axis of rotation to the electron circular path plane by about $10^{\circ}-11^{0}$ to the West, which corresponds the modern magnetic axis of Earth.

It is important to notice, that the suggested model allows to explain the causes of smallness or absence of magnetic fields of the other Solar System planets more correctly. In particular, any cooled planet with a cold metal core can have only a relict magnetic field.

\section{Conclusions}

The article shows that the Earth's body has an advantageous combination of such physical elements as the electroconductivity of the metal core and the temperature difference between the planet center and the lower mantle, which is determined by the geotemperature gradient. It is known from the physics, that interaction of those factors inevitably leads to appearance of both thermo e.m.f. 
between the shell boundaries and radially directed thermoelectrical currents of high value $\left(3.52 \times 10^{9} \mathrm{~A}\right.$, see Table 2$)$ because there are electrons in the core with sum mass of $5.1 \times 10^{19} \mathrm{~kg}$. The latter's moving cause appearance of the primary toroidal magnetic field, which is spherically asymmetric because of the thermo e.m.f. and the Earth's inertial forces. The secondary poloidal field is self-generated through the central channel in the toroidal field and is dipole with two oppositely directed magnetic poles.

Thermoelectrical currents energy, as the calculations show, is enough not only for generating the Earth's main dipole magnetic field on its early formation phase, but for maintaining it at the modern level of $(3-5) \times 10^{-5} \mathrm{~T}$ for a long time.

Thermoelectrical model of the Earth's geomagnetic field is a brand new one and it is close enough to the real thermoelectrical processes of Earth. The latter are universal from the physical point of view and proceed inside our planet according to the known physical laws, which do not need any theoretical limitations or additions for the model to function. For the first time the considered EMF model in comparison with the magnetohydrodynamo model can give physically and logically reasonable answers to the questions related to the behavior of a geomagnetic field in space and time. In particular, this model lets us explain the cause of the magnetic fields inversion, forecasts the magnitude of the residual (mantle) magnetic field during the polarity reversal and cyclic change of warming and cooling periods, it also clarifies the magnitude of the Earth's core electroconductivity and structure, allows to use a new and physically justified mechanism for calculating electrical and, indirectly, lithological characteristics of the Solar system planets. The latter, i.e. inversion problem solving, is likely if the magnetic fields of those planets are measures beforehand by spacecraft.

For the first time the temperature which the bottom surfaces of the continents and oceans bottom warm up to in case when the core's thermocurrents move to the lower mantle was calculated using the thermoelectrical model of the Earth's magnetic field.

Nevertheless, noe the considered thermoelectrical model of the Earth's magnetic field is on its first stage, so this is a protomodel. It is based on the description of a homogeneous structure of a magnetic field, which should be the reason for developing a real heterogeneous model, using differential equations.

\section{Acknowledgements}

Thanks to Abramovich S.A. for checking mathematical calculations and Proskurnina T. V. for efforts to translate the manuscript to English.

\section{References}

[1] Rikitake, T. (1966) Electromagnetism and the Earth's Interior 308. Elsevier Pub. Co.

[2] Bourgoin, M., Odier, P., Pinton, J.F. and Ricard, Y. (2004) An Iterative Study of Time Independent Induction Effects in Magnetohydrodynamics. Physics of Fluids, $16,2529-2547$. 
[3] Giesecke, A., et al. (2010) Electromagnetic Induction in Non-Uniform Domains. Geophysical \& Astrophysical Fluid Dynamics, 104, 505-529. https://doi.org/10.1080/03091929.2010.507202

[4] Gailitis, A., Lielausis, O., Platacis, E., Gerbeth, G. and Stefani, F. (2003) The Riga Dynamo Experiment. Surveys in Geophysics, 24, 247-267. https://doi.org/10.1023/A:1024851818821

[5] Verhille, G., Plihon, N., Bourgoin, M., Odier, P. and Pinton, J.F. (2010) Laboratory Dynamo Experiments. Space Science Reviews, 152, 543-564. https://doi.org/10.1007/s11214-009-9546-1

[6] Sokolov, D.D., Stepanov, R.A. and Frik, P.G. (2014) Dynamo: From Astrophysical Models to Laboratory Experiment. Success of Physical Science, 184, 313-335.

[7] Dolginov, A.Z. (1987) Origins of Magnetic Fields of Earth and Celestial Bodies. Success of Physical Science, 152, 231-262.

[8] Zeldovich, J.B. and Ruzmaikin, A.A. (1987) Hydromagnetic Dynamo as a Source of Planetary, Solar and Galactic Magnetism. Success of Physical Science, 152, 263-284.

[9] Arseniev, S.A. (2015) Theoretical Modeling of Main Magnetic Field of Earth and Planets. Actual Problems of Humanitarian and Natural Science, 4, 313-321. http://publikacia.net/archive/2015/4/2/94

[10] Elsasser, W.M. (1939) On the Origin of the Earth's Magnetic Field. Physical Review, 55, 489-498. https://doi.org/10.1103/PhysRev.55.489

[11] Vestine, E.H. (1954) The Earth's Core. Transactions-American Geophysical Union, 35, 63-72.

[12] Runcorn, S.K. (1954) The Earth's Core. Transactions-American Geophysical Union, 35, 49-63. https://doi.org/10.1029/TR035i001p00049

[13] Dmitriev, A.N. (1980) About a Possible Reason of Existence of Two Poles of Natural Polarized Conductors. Exploratory Geophysics, 88, 125-129.

[14] Dmitriev, A.N. (2007) Geological and Geophysical Basis for Research of Electrically Polarized Objects-Oil and Ore Deposits 226 Tyumen: TGU.

[15] Dmitriev, A.N. (2016) A New Look on the Nature of the Earth's Magnetic Field. IOP Conference Series: Earth and Environmental Science, 44, Article ID: 022001. https://doi.org/10.1088/1755-1315/44/2/022001

[16] Zharkov, V.N. (1983) Inner Structures of the Earth and Other Planets 416 M. Nauka.

[17] Magnitsky, A. (2006) Inner Structure and Physics of the Earth 389 M. Nauka.

[18] Kuznetsov, V. (2011) Physics of Earth 842 Novosibirsk.

[19] Uffen, R.J. (1952) A Method of Estimating the Melting Point Gradient in the Earth's Mantle. Transactions-American Geophysical Union, 33, 893-896. https://doi.org/10.1029/TR033i006p00893

[20] Tozer, D.C. (1959) The Electrical Properties of the Earth's Interior. Physics and Chemistry of the Earth, 3, 414-436.

[21] Anzellini, S., Dewaele, A., Mezouar, M., Loubeyre, P. and Morard, G. (2013) Melting of Iron at Earth's Inner Core Boundary Based on Fast X-Ray Diffraction. Science, 340, 464-466. https://doi.org/10.1126/science.1233514

[22] Kuznetsov, V. (2008) Introduction to the Hot Earth's Physics 366 IKIR.

[23] Kalashnikov, S.G. (1977) Electricity 592 M. Nauka.

[24] Saveliev, I. (1970) General Physics Course. Vol. II 336 M. Nauka.

[25] Martinson, L.K. and Smirnov, E. (2004) Quantum Physics. 496 M. MGTU im. N.E. 
Baumana.

[26] Pavlov, P.V. and Chochlov, A.F. (2000) Physics of Solid Bodies. Textbook 494 M. Vysshaya shkola.

[27] Tyushev, A.N. (2011) Physics Lections: Part 5. Quantum Physics 167 Novosibirsk, SGGA.

[28] Pasynkov, V.V. and Sorokin, V.S. (2001) Materials of Electronic Technics. Series: Textbooks for Universities 368 Lan.

[29] Lifshits, I.M., Azbel, M.Y. and Kaganov, M.I. (1971) Electronic Theory of Metals 416 M. Nauka.

[30] Matveev, A.N. (1983) Electricity and Magnetism. 464 M. Vysshaya Shkola.

[31] Juravlev, V.A. (2002) Quantum Theory of Metals Theory Lections 240 M. Computer Studies Institute.

[32] Plotkin, V.V., Dyadkov, P.G. and Ovchinnikov, S.G. (2014) Identification of Phase Transition of Magnesia Wustite in Lower Mantle: Inversion of Geomagnetic Data. Geology and Geophysics, 55, 1436-1445.

[33] Martynenko, T.P., Odincova, G.A., Pronina, V.S. and Sokolova, E.U. (2008) Practical Physics: Quantum Physics. Physics of Solid Bodies and Nuclear Physics Elements 210 M. VVIA im. Prof. N.E. Jukovskogo.

[34] Loper, D.E. (1984) Structure of the Core and Lower Mantle. Advances in Geophysics, 26, 1-34.

[35] Hoffman, D.L. and Simmons, A. (2008) The Resilient Earth 404 BookSurge Publishing.

[36] Hansen, J., Sato, M., Russell, G. and Kharecha, P. (2013) Climate Sensitivity, Sea Level and Atmospheric Carbon Dioxide. https://doi.org/10.1098/rsta.2012.0294

[37] Kotlyakov, V.M. (2012) Causes and Results of Modern Climate Changes. Solar and Earth's Physics, 21, 110-114.

[38] Zachos, J., Pagani, M., Sloan, L., Thomas, E. and Billups, K. (2001) Trends, Rhythms, and Aberrations in Global Climate 65 Ma to Present. Science, 292, 686693. https://doi.org/10.1126/science.1059412

[39] Yanovsky, B.M. (1978) Terrestrial Magnetism. Parts 1, 2. 591 L. GITTL.

[40] Kolesnikov, L.V. and Yudin, A.L. (2003) Materials Science. Part 2. Methodical Toolkit for Laboratory Practice. 82 Kemerovo.

[41] Boriev, I.A. (2012) Quantitative Relationship of Impulse's Relaxation Time When Transferring Electrons in Substance under Effect of Electricity and Time of Their Mean Free Path. News of Science Academy, Series Power Engineering, 3, 105-112.

[42] Monin, A.S. (1977) History of Earth 228 L. Science.

[43] Royer, D.L., Berner, R.A., Montañez, I.P., Tabor, N.J. and David, J. (2004) $\mathrm{CO}_{2}$ as a Primary Driver of Phanerozoic Climate. GSA Today, 14, 4-10. https://doi.org/10.1130/1052-5173(2004)014<4:CAAPDO >2.0.CO;2

[44] Serebrennikov, V.B. (2008) Temperature and Climatic Cyclicity in Anthropogen and Its Consequences. Peter's Academy News. 9. http://togeo.ru/main/serebrennikov/articles/arctida-rusy/chapter-02.html

[45] Korzun, V.A. (2009) Global Warming-Reality or Politicized Mith? (Perspectives of Development a "Green Economics" in Russia) 191 M. IMEMO RAN.

[46] Petrovich, A. (2011) Canon of Ice Age. Milutin Milankovich and Astronomic Theory of Climate Changes 132 St. Petersburg. Nestor-Istoriya.

[47] Prigogine, I. and Nicolis, G. (1977) Self-Organization in Non-Equilibrium Systems: 
From Dissipative Structures to Order through Fluctuations, J. Wiley\& Sons, New York.

[48] Butler, S.L., Peltier, W.R. and Costin, S.O. (2005) Numerical Models of the Earth's Thermal History: Effects of Inner-Core Solidification and Core Potassium. Physics of the Earth and Planetary Interiors, 152, 22-42.

[49] Korotkih, A.G. and Shamanin, I. (2007) Hydrodynamics and Heat Exchange Basics in Nuclear Reactors. Textbook 117 Tomsk State University.

[50] Micheev, M.A. and Micheeva, I.M. (1977) Basics of Heat Exchange. 2nd Edition, stereotipe $344 \mathrm{M}$. Energiya.

[51] Isachenko, V.P., Osipova, V.A. and Sukomel, A.S. (1981) Heat Exchange 416 M. Energoizdat.

[52] Buchmirov, V.V., Rakutina, D.V. and Solnyshkova, J.S. (2013) Nonstationary Thermal Conductivity. Reference Materials for Solving Exercicez 36 Ivanovo.

[53] Lykov, A. (1967) Theory of Thermal Conductivity. 599 M. Vysshaya shkola.

[54] Stepanov, A.A. and Starchenko, S. (2005) Spherically Simmetric Heat Transfer in Mantle. Electronic Journal "Researched in Russia”, 8, 1760-1770.

http://www.stroycab.ru/punishment-spbcap7-1.perl 


\section{Additional Information}

The manuscript "Thermoelectric currents of earth's core generate the earth's magnetic field" was not published in any magazine and it is not being edited in any editorial office.

An article close by meaning was published in 2016:

Dmitriev A. N. A New Look On the Nature of the Earth's Magnetic Field//IOP Conf. Series: Earth and Environmental Science 44 (2016) 022001.

DOI:10.1088/1755-1315/44/2/022001

I made the manuscript on my own in the Tyumen Industrial University, where I am working. Here is no competing finantial or any other interests of any organization as I did not get any subsidies, grants or ordinary shares. I, A.N. Dmitriev, am the only author of the manuscript and there is no legal claim to me from anyone. The manuscript author, A. N. Dmitriev.

Submit or recommend next manuscript to SCIRP and we will provide best service for you:

Accepting pre-submission inquiries through Email, Facebook, LinkedIn, Twitter, etc. A wide selection of journals (inclusive of 9 subjects, more than 200 journals)

Providing 24-hour high-quality service

User-friendly online submission system

Fair and swift peer-review system

Efficient typesetting and proofreading procedure

Display of the result of downloads and visits, as well as the number of cited articles

Maximum dissemination of your research work

Submit your manuscript at: http://papersubmission.scirp.org/

Or contact ijg@scirp.org 